\title{
Relationships between pre-sunset electrojet strength, pre-reversal enhancement and equatorial spread-F onset
}

\author{
J. Uemoto ${ }^{1}$, T. Maruyama ${ }^{1}$, S. Saito ${ }^{2}$, M. Ishii ${ }^{1}$, and R. Yoshimura ${ }^{3}$ \\ ${ }^{1}$ National Institute of Information and Communications Technology, Tokyo, Japan \\ ${ }^{2}$ Electronic Navigation Research Institute, Tokyo, 182-0012, Japan \\ ${ }^{3}$ Kitasato University, Kanagawa, 228-8555, Japan
}

Received: 20 June 2009 - Revised: 10 December 2009 - Accepted: 21 December 2009 - Published: 8 February 2010

\begin{abstract}
The virtual height of the bottom side F-region $\left(h^{\prime} F\right)$ and equatorial spread-F (ESF) onsets at Chumphon $\left(10.7^{\circ} \mathrm{N}, 99.4^{\circ} \mathrm{E} ; 3.3^{\circ} \mathrm{N}\right.$ magnetic latitude) were compared with the behaviour of equatorial electrojet (EEJ) ground strength at Phuket $\left(8.1^{\circ} \mathrm{N}, 98.3^{\circ} \mathrm{E} ; 0.1^{\circ} \mathrm{N}\right.$ magnetic latitude) during the period from November 2007 to October 2008. Increase in the F-layer height and ESF onsets during the evening hours were well connected with the EEJ ground strength before sunset, namely, both the height increase and ESF onsets were suppressed when the integrated EEJ ground strength for the period from 1 to $2 \mathrm{~h}$ prior to sunset was negative. The finding suggests observationally that the pre-sunset E-region dynamo current and/or electric field are related to the F-region dynamics and ESF onsets around sunset.
\end{abstract}

Keywords. Ionosphere (Electric fields and currents; Equatorial ionosphere; Ionospheric irregularities)

\section{Introduction}

The vertical $\boldsymbol{E} \times \boldsymbol{B}$ drift driven by the zonal electric field and horizontal northward magnetic field significantly affects the structure and dynamics of the equatorial F-region ionosphere. The vertical $\boldsymbol{E} \times \boldsymbol{B}$ drift is generally upward during the daytime and downward during the nighttime. During the daytime, the eastward electric field is mainly generated by the E-region dynamo. The dynamo electric field simultaneously drives a zonal current in the E-region. Such a current is intensified in the vicinity of the magnetic equator with the range of a few degrees and is called the equatorial electrojet (EEJ) (Chapman, 1951). EEJ causes large variations, typically several tens $\mathrm{nT}$, in the geomagnetic field, and it has

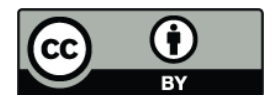

Correspondence to: J. Uemoto

(juemoto@nict.go.jp) been extensively studied by analysing the ground-based magnetometer data (e.g., Doumouya et al., 1998).

It is well-known that the reversal of the eastward electric field to westward around sunset is often accompanied by a strengthened eastward electric field called the pre-reversal enhancement (PRE), and its amplitude and time depend on the solar and magnetic activities, season and longitude (e.g., Fejer and Scherliess, 1997, 2001). A mechanism of PRE has been investigated with numerical techniques, and the Fregion dynamo has been considered as the primary origin of PRE (e.g., Eccels, 1998; Heelis, 2004). However, detailed physical processes connecting the F-region dynamo and PRE appear to be complicated, and several explanations have been proposed (e.g., Rishbeth, 1971; Farley et al., 1986; Haerendel and Eccles, 1992; Eccles, 1998). Haerendel and Eccles (1992) investigated a current system around sunset by inputting arbitrary zonal electric field variations in their model. They found that the dayside EEJ flows into a night side region and that a vertical divergent current of EEJ connects to the vertical F-region dynamo current. They proposed that the current connection demands EEJ to flow in a low conductivity E-region around sunset, and then an additional eastward electric field strengthening PRE can originate.

Equatorial spread-F (ESF) irregularity is a plasma density irregularity occurring in the F-region ionosphere after sunset. Since the ESF irregularity causes severe disturbances for various communication and navigation systems, a precise forecast of ESF onsets is important from a point-of-view of space weather. Although an initial phase of ESF development has been explained by the linear Rayleigh-Taylor instability theory (e.g., Sultan, 1996), the precise forecast of ESF onsets has not been established. One of the reasons is that the seeding mechanism of an initial perturbation which is necessary for ESF onsets has not been fully understood, although the gravity wave has been suggested as the possible seeding source (Abdu, 2001, and references therein). The other is the fact that various physical processes control the ESF

Published by Copernicus Publications on behalf of the European Geosciences Union. 
development (Abdu, 2001). Among the various processes, PRE is considered to be the primary process acting on ESF development (e.g., Abdu, 2001); it is then pointed out that the precise knowledge of the day-to-day variability of PRE can help in understanding that of ESF onsets.

Recently, relationships between the daytime EEJ, PRE strength and ESF onset have been extensively investigated, particularly in India. Dabas et al. (2003) compared the virtual height of the bottom side F-layer $\left(h^{\prime} F\right)$ on ionograms and the $\boldsymbol{E} \times \boldsymbol{B}$ drift $\left(d h^{\prime} F / d t\right)$ during evening hours with the EEJ ground strength observed at 11:00 IST (Indian standard time, $\mathrm{IST}=\mathrm{UT}+5.5 \mathrm{~h}$ ) in February 1980 and September and October 1989. They found that the daytime EEJ ground strength and both the evening $h^{\prime} F$ and $\boldsymbol{E} \times \boldsymbol{B}$ drift show good, positive correlations. Tulasi Ram et al. (2007) examined the highest $h^{\prime} F$, ESF onset from 18:00 to 21:00 IST, and the integrated EEJ ground strength (IEEJ) from 07:00 to 17:00 IST in March for the period 2001 to 2005 . They found that the highest $h^{\prime} F$, ESF onset, and IEEJ show good, positive correlations. The relationships they found can help in forecasting ESF onsets because the EEJ ground strength before sunset can be measured prior to ESF onsets. Then, the relationships should be examined in more detail whether they are valid in any season and longitude. On the other hand, Haerendel and Eccles (1992) found, by performing calculations, that the dayside EEJ flows into the night side region and that the vertical divergent current of EEJ connects to the vertical Fregion dynamo current. The existence of the divergent current of EEJ has been observationally verified by Denardini et al. (2006). Thus, EEJ just before sunset could be connected to PRE. However, the relationship between the EEJ ground strength, limited to pre-sunset hours, and PRE has not been observationally investigated on a day-to-day basis as far as the authors are aware.

To investigate the relationships between the PRE strengths, ESF onsets and EEJ ground strengths around sunset hours, we analyzed ionograms and magnetometer data obtained in Southeast Asia.

\section{Data set and analysis methods}

ESF onsets and PRE strengths were derived by analysing ionograms obtained at Chumphon (CPN: $10.7^{\circ} \mathrm{N}, 99.4^{\circ} \mathrm{E}$; $3.3^{\circ} \mathrm{N}$ magnetic latitude) every $15 \mathrm{~min}$ during the period from 18:00 to 21:00 THA (Thailand standard time, $\mathrm{THA}=\mathrm{UT}+7 \mathrm{~h}$ ). The details of the ionosonde observation are provided elsewhere (e.g., Maruyama et al., 2007). In this study, ESF days are defined only when ESF is detected before 21:00 THA. ESF onsets after 21:00 THA are ignored because ESF onsets after 21:00 THA mainly accompany fossil plasma bubbles (e.g., Saito and Maruyama, 2006) except for magnetically disturbed conditions. Bittencourt and Abdu (1981) reported that the time variation of $h^{\prime} F\left(d h^{\prime} F / d t\right)$ agrees well with the $\boldsymbol{E} \times \boldsymbol{B}$ drift of PRE when $h^{\prime} F$ exceeds
$300 \mathrm{~km}$. Many earlier studies have utilized $d h^{\prime} F / d t$ for evaluating the $\boldsymbol{E} \times \boldsymbol{B}$ drift of PRE with ionosonde observation (e.g., Rama Rao et al., 1997). During the nighttime, the lower edge of the F-region echo trace at CPN is generally below the frequency of $2.0 \mathrm{MHz}$, which is the start frequency of the ionosonde installed at CPN. Considering the retardation effect on the echo trace, $h^{\prime} F$ scaled at the lower frequency is more adequate to evaluate the $\boldsymbol{E} \times \boldsymbol{B}$ drift of PRE, on the contrary, scaling $h^{\prime} F$ at the lower frequency is more likely to be interfered by the sporadic E-layer. In this context, $h^{\prime} F$ at the frequency of $2.5 \mathrm{MHz}$ is manually scaled to derive the PRE strength as performed by earlier studies (e.g., Saito and Maruyama, 2006; Maruyama et al., 2007). On the basis of the findings by Bittencourt and Abdu (1981), a peak of $h^{\prime} F$ during the period from 18:00 to 21:00 THA reflects a timecumulative $\boldsymbol{E} \times \boldsymbol{B}$ drift of PRE. We adopted a peak of $h^{\prime} F$ from 18:00 to 21:00 THA as the PRE strength. It should be noted that $h^{\prime} F$ derived in this study was often below $300 \mathrm{~km}$ (see Fig. 1), in which case, $h^{\prime} F$ is affected by the production and loss of plasma as well as the $\boldsymbol{E} \times \boldsymbol{B}$ drift of PRE. Then, the peaks of $h^{\prime} F$ are not utilized to discuss the PRE strengths quantitatively but qualitatively. On the other hand, the scaling of $h^{\prime} F$ becomes impossible when a strong sporadic E-layer occurs. We used the $h^{\prime} F$ data on certain days for analyses when more than half of $h^{\prime} F$ during the period from 18:00 to 21:00 THA can be scaled.

In this study, the EEJ current was evaluated by using its magnetic effect at the ground level referred as the EEJ ground strength (Denardini et al., 2009). The EEJ ground strength was calculated from $\mathrm{H}$-components that were obtained from magnetometers installed at Phuket (PKT: $8.1^{\circ} \mathrm{N}, 98.3^{\circ} \mathrm{E}$; $0.1^{\circ} \mathrm{N}$ magnetic latitude) and at Kototabang (KTB: $0.2^{\circ} \mathrm{S}$, $100.3^{\circ} \mathrm{N} ; 10.0^{\circ} \mathrm{S}$ magnetic latitude). We used 5 min values calculated from $1 \mathrm{~min}$ ones for analyses, since EEJ variations with a time scale more than $10 \mathrm{~min}$ are required in this study. The EEJ ground strength was estimated by subtracting the $\mathrm{H}$-component at KTB outside the EEJ region from that at PKT inside the EEJ region according to many previous studies (e.g., Mayaud, 1977; Denardini et al., 2009). The subtraction was performed to minimize the difference between the $\mathrm{H}$-components at PKT and KTB over the period from 21:00 to 05:00 LT at PKT (LT at PKT is 6.6 h ahead of UT). The residue of the difference, during the period from 21:00 to 05:00 LT at PKT, tended to become large when the daily AP index was high. When the residue is large, the estimated EEJ ground strength probably contains a large error. Then, we used the EEJ ground strength on certain days when the average of the residue is less than $5 \mathrm{nT}$ and the daily AP index at PKT is less than 15.

We investigated the relationships between PRE, ESF and EEJ for 240 days when both the requirements of ionogram and magnetometer data are met for analyses for the period from November 2007 to October 2008. 


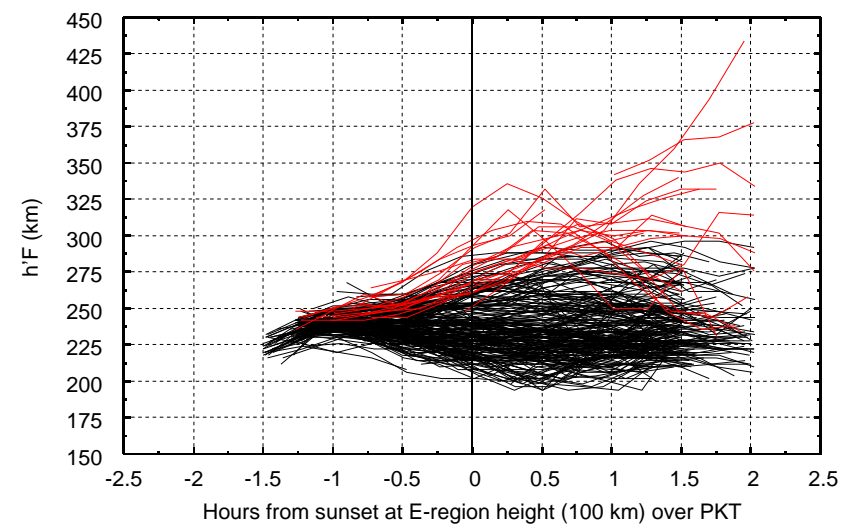

Fig. 1. $h^{\prime} F$ variations at $\mathrm{CPN}$ during the local-time period from 18:00 to 21:00 THA. It should be noted that the horizontal axis is hours from sunset at E-region height $(100 \mathrm{~km})$ over PKT. The red lines indicate $h^{\prime} F$ variations on certain days when the peak of $h^{\prime} F$ exceeds $300 \mathrm{~km}$.

\section{Results}

Figure 1 shows the $h^{\prime} F$ variations at $\mathrm{CPN}$ for the period from 18:00 to 21:00 THA. The red lines correspond to the $h^{\prime} F$ variation when the peak of $h^{\prime} F$ exceeded $300 \mathrm{~km}$ and PRE was relatively strong even for the low solar activity period. As the sunset time, measured in local meantime, varies over approximately $1 \mathrm{~h}$ depending on the day of the year (see Fig. 4), the $h^{\prime} F$ variations are arranged according to sunset at E-region height $(100 \mathrm{~km})$ over PKT. Figure 1 indicates that PRE starts to develop before sunset at E-region height. We adopt the integrated EEJ ground strength from $2 \mathrm{~h}$ to $1 \mathrm{~h}$ prior to sunset at E-region height as the EEJ ground strength just before or around the time when PRE starts to develop. The integrated EEJ ground strength from $2 \mathrm{~h}$ to $1 \mathrm{~h}$ prior to sunset at E-region height is referred to as the pre-sunset IEEJ, while that from 07:00 to 17:00 THA is referred to as the daytime IEEJ.

Figure 2 shows the scatter plots of the peak $h^{\prime} F$ of PRE versus the daytime IEEJ (panel a) and the pre-sunset IEEJ (panel b). Solid and open circles indicate the ESF and no ESF days, respectively. Figure 3 shows how the ESF occurrences depend on the peak $h^{\prime} F$ of PRE (panel a), daytime (panel b) and evening IEEJ (panel c). Figure $3 a$ indicates that ESF onsets tend to be frequently as the peak $h^{\prime} F$ of PRE becomes high as reported by earlier studies (e.g., Abdu, 2001, and references therein). As shown in Fig. 2a and Fig. 3b, clear relationships between the PRE strength, ESF onsets and the daytime IEEJ through a year were not found in Southeast Asia, although the direct relationship between the PRE strength and the daytime EEJ ground strength around the equinox seasons in the Indian sector was found (Dabas et al., 2003; Tulasi Ram et al., 2007). On the other hand, interesting relationships between the PRE strength, ESF onset and the pre-sunset IEEJ were found; PRE tends to be sup-
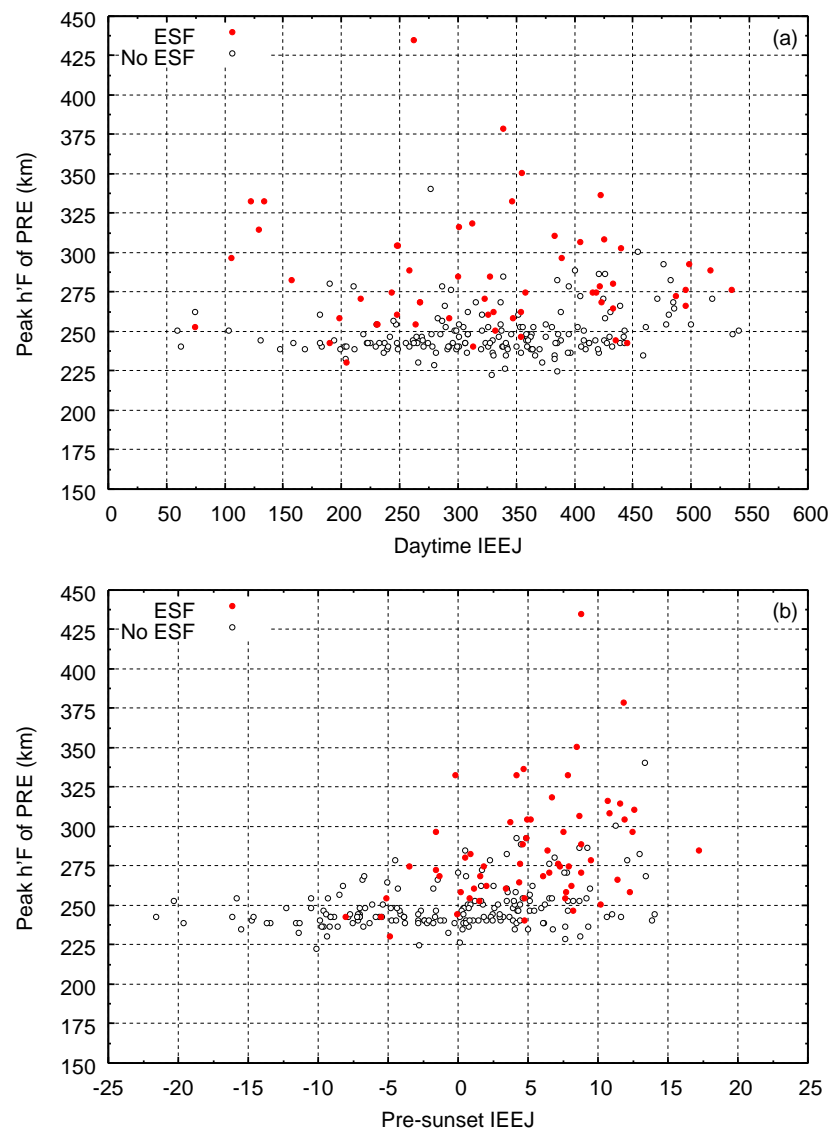

Fig. 2. Scatter plots of peak $h^{\prime} F$ of PRE at CPN versus daytime (a) and pre-sunset (b) IEEJ at PKT. Solid and open circles indicate the occurrence and non-occurrence of ESF.

pressed when the pre-sunset IEEJ is negative (Fig. 2b). ESF detection is also less frequent when the pre-sunset IEEJ is negative (Fig. 2b and Fig. 3c). The primary cause of suppression of ESF onsets appears to be the PRE strength, since the most important driver of ESF development is considered to be the PRE strength. When the pre-sunset IEEJ is positive, the peak $h^{\prime} F$ and ESF onsets scatter. In other words, the PRE strength and ESF onsets cannot be predicted solely by the pre-sunset IEEJ when the pre-sunset IEEJ is positive. This implies that the PRE strength is affected by various components, such as the F-region neutral wind and flux tube-integrated conductivities (e.g., Heelis, 2004; Prakash et al., 2009) and that the seed perturbation and the physical processes such as the meridional neutral wind also control ESF onsets (Abdu, 2001).

Figure 4 shows the seasonal and local-time variations of the EEJ ground strength as a contour plot. The red colour indicates the positive values and the blue colour indicates the negative ones, or the counter electrojet (CEJ). The CEJ, classified as the evening CEJ by Alex and Mukherjee (2001), started to develop around 15:00 LT at PKT, as shown in the figure. The evening CEJ occurred frequently in the June 

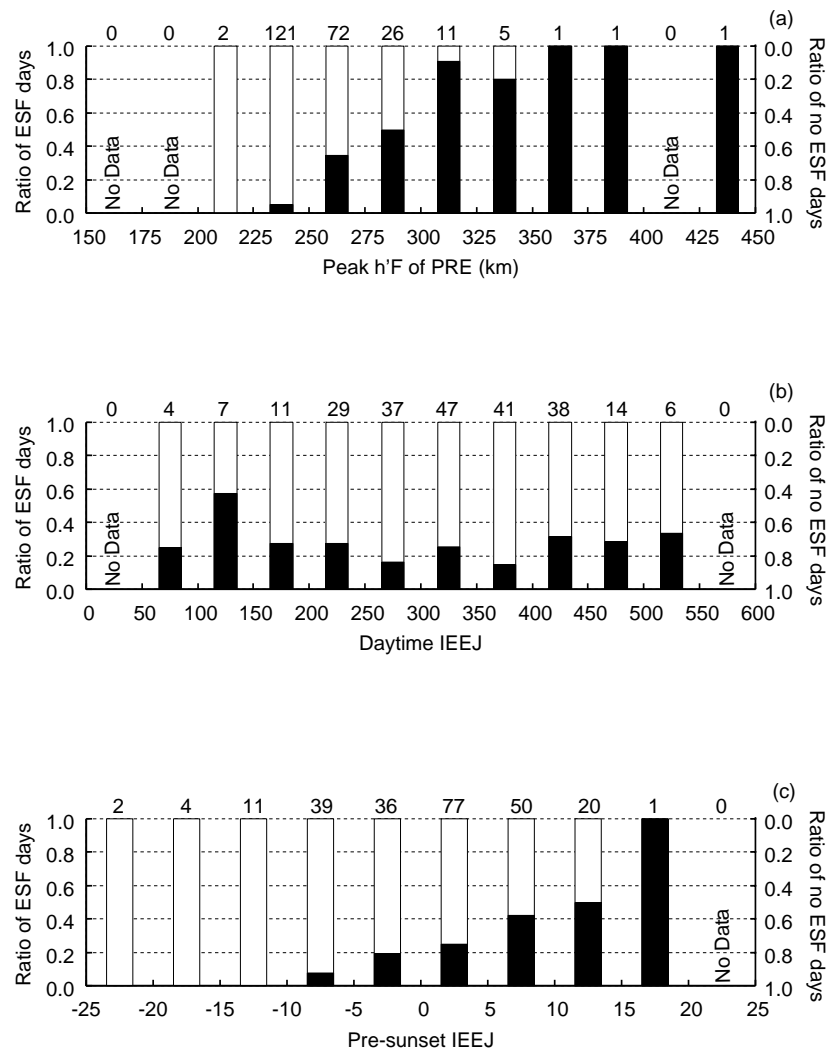

Fig. 3. Dependence of the ESF occurrences on the peak $h^{\prime} F$ of PRE (a), daytime (b) and pre-sunset IEEJ (c). Solid and open bars indicate the ratios of ESF and no ESF days to the total number of days contained in each bin. The total number of days in each bin is given on the top of each bar.

solstice season, moderately in the equinox seasons and less frequently in the December solstice season. The local-time of the evening CEJ occurrence also showed a seasonal dependence and it tended to occur in later local-times in the June solstice season. The integral range for calculating the presunset IEEJ is an area lying between the two thin curves that correspond to the local-time 1 to $2 \mathrm{~h}$ prior to sunset at the E-region height. As understood by comparing the evening CEJ with the integral range, it is the evening CEJ occurring in later local-times that makes the pre-sunset IEEJ negative. Therefore, it can be pointed out that PRE is suppressed when the evening CEJ occurs in later local-times.

\section{Discussion}

PRE and ESF onsets are found to be suppressed when the evening CEJ occurred in later local-times and when the presunset IEEJ was negative. Considering that the PRE strength plays a primary role in ESF development (e.g., Abdu, 2001), it is natural that ESF onsets were suppressed on the evening of CEJ days. Two possible explanations of the relationship

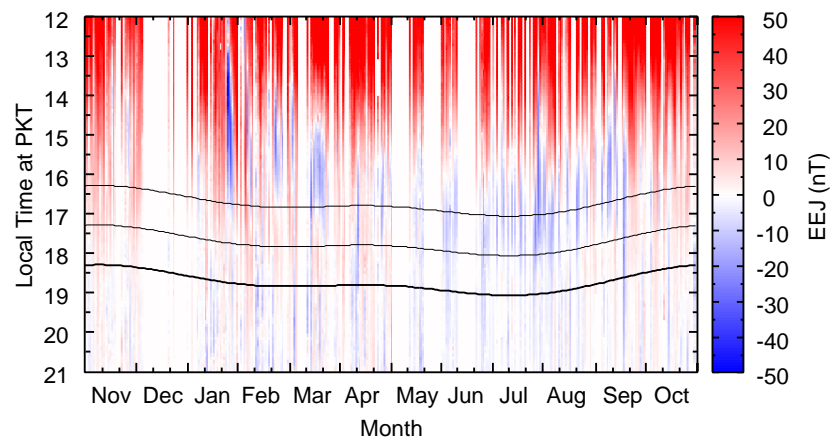

Fig. 4. Contour plot of the EEJ ground strength during the period from November 2007 to October 2008. The thick curve indicates sunset at E-region height. Two thin curves indicate the local-time of $2 \mathrm{~h}$ and $1 \mathrm{~h}$ prior to sunset, respectively.

between the PRE strength and the pre-sunset IEEJ are suggested. One is a current connection between the daytime EEJ and the vertical current in the F-region around sunset proposed by Haerendel and Eccles (1992). The other is a connection through the modification of plasma density distribution in the equatorial F-region around sunset (Prakash et al., 2009) by the zonal electric field generated in the pre-sunset E-region dynamo.

Haerendel and Eccles (1992) suggest that EEJ is required to flow into a low conductivity region around sunset for establishing the current connection between the daytime EEJ and the vertical current generated by the F-region dynamo around sunset. Subsequently, an additional eastward electric field that strengthens PRE can originate. Denardini et al. (2006) observationally verified the existence of the divergent current of EEJ. When the evening CEJ occurs, a westward current is considered to flow in the pre-sunset E-region, in which case, the strengthening PRE proposed by Haerendel and Eccles (1992) would not occur. The present result is consistent with the current continuity hypothesis between the pre-sunset E-region and F-region around sunset proposed by Haerendel and Eccles (1992). It should be noted that the present analyses did not directly exhibit spatial variations of the current system, since the pre-sunset IEEJ and the PRE strength around sunset were obtained at the same longitude at different times. Several earlier models and observational studies have proposed that the evening CEJ is caused by semi-diurnal tides (e.g., Hanuise et al., 1983; Alex and Mukherjee, 2001; Gurubaran, 2002). The semi-diurnal tides are not likely to vary dramatically within a few hours or several tenths of longitudes. Therefore, longitudinal and temporal variations of the current system are considered to be equivalent.

Relationships between plasma density distribution in a meridional plane, the PRE strength and ESF onsets have been extensively investigated. Thampi et al. (2008) found, by analysing total electron content (TEC) values, that ESF 
tends to occur when the equatorial ionization anomaly (EIA) is well developed and symmetrical in both the hemispheres. Prakash et al. (2009) suggested, by performing model calculations, that PRE tends to be strengthened with the increasing flux tube integrated conductivity of the tropical F-region. A statistical analysis performed by Rama Rao et al. (1997) showed that the peak density of the F2-layer near and inside the EIA crests was strengthened during evening hours on ESF days. Stolle et al. (2008) investigated a typical response time of observed EIA to EEJ variations and they showed that EIA decays significantly within approximately $2 \mathrm{~h}$ after CEJ onsets. Considering the results reported by Stolle et al. (2008), the evening CEJ modifies the plasma density distribution around and inside the EIA crests around sunset, since the evening CEJ that makes the pre-sunset IEEJ negative already starts in the afternoon (see Fig. 4). The present results are also consistent with the hypothesis explaining PRE variations through the modification of the plasma density distribution in the equatorial F-region that is caused by the pre-sunset E-region dynamo electric field.

Although it is difficult to determine which mechanism is important to connect the pre-sunset IEEJ and PRE/ESF, the present findings are significant from the point-of-view of space weather because the pre-sunset IEEJ can be observationally determined prior to ESF hours and can be one of the many control factors of ESF onsets.

\section{Summary}

The PRE strengths and ESF onsets at CPN were compared with the daytime and pre-sunset IEEJ at PKT for the period from November 2007 to October 2008. The PRE strengths and ESF onsets are found to be suppressed when the presunset IEEJ is negative owing to the evening CEJ. The finding suggests observationally that the E-region dynamo current and/or electric field before sunset can be related to the F-region dynamics and ESF onsets around sunset. Two possible mechanisms were examined. One is the current connection between EEJ and the F-region dynamo vertical current; when the evening CEJ occurs, the strengthening of PRE proposed by Haerendel and Eccels (1992) would not occur. The other is the E-region dynamo effect on the meridional plasma density distribution inside the EIA crests that affects the PRE strength (Prakash et al., 2009) and the ESF onsets (e.g., Rama Rao et al., 1997). The current results are consistent with both the mechanism. It is difficult to determine which mechanism is important from the present study. To clarify which mechanism is effective, simultaneous observation of the PRE strength and the pre-sunset IEEJ at two locations that are separate by approximately $15^{\circ}$ to $30^{\circ}$ in longitude, and that of the PRE strength, pre-sunset IEEJ and plasma density distribution inside the EIA crests in a meridional plane are required. Although the precise forecast of ESF onsets requires the examination of all the physical pro- cesses related to the ESF development and the seeding mechanism of the initial perturbation in detail, it should be emphasized that the findings are significant from the point-of-view of space weather because the pre-sunset IEEJ can be observationally determined prior to ESF onsets.

Acknowledgements. The ionosonde at Chumphon and the magnetometer at Phuket are operated under agreements between NICT, Japan and King Mongkut's Institute of Technology Ladkrabang (KMITL), Thailand. The magnetometer at Kototabang has been operated in collaboration among the Solar-Terrestrial Environment Laboratory (STEL), Nagoya University, Japan, the Research Institute for Sustainable Humanosphere (RISH), Kyoto University, Japan and the National Institute of Aeronautics and Space (LAPAN), Indonesia.

Topical Editor M. Pinnock thanks A. Patra and I. Batista for their help in evaluating this paper.

\section{References}

Abdu, M. A.: Outstanding problems in the equatorial ionospherethermosphere electrodynamics relevant to spread F, J. Atmos. Solar Terr. Phys., 63, 869-884, 2001.

Alex, S. and Mukherjee, S.: Local-time dependence of the equatorial counter electrojet effect in a narrow longitudinal belt, Earth Planets Space, 53, 1151-1161, 2001.

Bittencourt, J. A. and Abdu, M. A.: A theoretical comparison between apparent and real vertical ionization drift velocities in the equatorial F region, J. Geophys. Res., 86, 2451-2454, 1981.

Chapman, S.: The equatorial electrojet as detected from the abnormal electric current distribution above Huancayo, Peru and elsewhere, Arch. Meteorol. Geophys. Bioklimatol., 44, 368-390, 1951.

Dabas, R. S., Singh, L., Lakshmi, D. R., Subramanyam, P., Chopra, P., and Garg, S. C.: Evolution and dynamics of equatorial plasma bubbles: Relationships to $\boldsymbol{E} \times \boldsymbol{B}$ drift, postsunset total electron content enhancements, and equatorial electrojet strength, Radio Sci., 38, 1075, doi:10.1029/2001RS002586, 2003.

Denardini, C. M., Abdu, M. A., de Paula, E. R., Wrasse, C. M., and Sobral, J. H. A.: VHF radar observations of the dip equatorial Eregion during sunset in the Brazilian sector, Ann. Geophys., 24, 1617-1623, 2006, http://www.ann-geophys.net/24/1617/2006/.

Denardini, C. M., Abdu, M. A., Aveiro, H. C., Resende, L. C. A., Almeida, P. D. S. C., Olmvio, Ê. P. A., Sobral, J. H. A., and Wrasse, C. M.: Counter electrojet features in the Brazilian sector: simultaneous observation by radar, digital sounder and magnetometers, Ann. Geophys., 27, 1593-1603, 2009, http://www.ann-geophys.net/27/1593/2009/.

Doumouya, V., Vassal, J., Cohen, Y., Fambitakoye, O., and Menvielle, M.: Equatorial electrojet at African longitudes: first results from magnetic measurements, Ann. Geophys., 16, 658666, 1998, http://www.ann-geophys.net/16/658/1998/.

Eccles, J. V.: Modeling investigation of the evening prereversal enhancement of the zonal electric field in the equatorial ionosphere, J. Geophys. Res., 103, 26709-26719, 1998. 
Farley, D. T., Bonelli, E., Fejer, B. G., and Larsen, M. F.: The prereversal enhancement of the zonal electric field in the equatorial ionosphere, J. Geophys. Res., 91, 13723-13728, 1986.

Fejer, B. G. and Scherliess, L.: Empirical models of storm time equatorial zonal electric fields, J. Geophys. Res., 102, 2404724056, 1997.

Fejer, B. G. and Scherliess, L.: On the variability of equatorial Fregion vertical plasma drifts, J. Atmos. Sol. Terr. Phys., 63, 893897,2001

Gurubaran, S.: The equatorial counter electrojet: Part of a worldwide current system?, Geophys. Res. Lett., 29, 1337, doi:10.1029/2001GL014519, 2002.

Haerendel, G. and Eccles, J. V.: The role of the equatorial electrojet in the Evening Ionosphere, J. Geophys. Res., 97, 1181-1192, 1992.

Hanuise, C., Mazaudier, C., Vila, P., Blanc, M., and Crochet, M.: Global dynamo simulation of ionospheric currents and their connection with the equatorial electrojet and counter electrojet: A case study, J. Geophys. Res., 88, 253-270, 1983.

Heelis, R. A.: Electrodynamics in the low and middle latitude ionosphere: a tutorial, J. Atmos. Solar Terr. Phys., 66, 825-838, 2004.

Maruyama, T., Kawamura, M., Saito, S., Nozaki, K., Kato, H., Hemmakorn, N., Boonchuk, T., Komolmis, T., and Ha Duyen, C.: Low latitude ionosphere-thermosphere dynamics studies with inosonde chain in Southeast Asia, Ann. Geophys., 25, 1569-1577, 2007, http://www.ann-geophys.net/25/1569/2007/.

Mayaud, P. N.: The equatorial counter-electrojet - a review of its geomagnetic aspects, J. Atmos. Terr. Phys., 39, 1055-1070, 1977.

Prakash, S., Pallamraju, D., and Sinha, H. S. S.: Role of the equatorial ionization anomaly in the development of the evening prereversal enhancement of the equatorial zonal electric field, J. Geophys. Res., 114, A02301, doi:10.1029/2007JA012808, 2009.
Rama Rao, P. V. S., Jayachandran, P. T., and Sri Ram, P.: Ionospheric irregularities-role of Equatorial Ionization Anomaly, Radio Sci., 32, 1551-1556, 1997.

Rishbeth, H.: Polarization fields produced by winds in the equatorial F-region, Planet. Space Sci., 19, 357-369, 1971.

Saito, S. and Maruyama, T.: Ionospheric height variations observed by ionosondes along magnetic meridian and plasma bubble onsets, Ann. Geophys., 24, 2991-2996, 2006, http://www.ann-geophys.net/24/2991/2006/.

Stolle, C., Manoj, C., Lühr, H., Maus, S., and Alken, P.: Estimating the daytime equatorial ionization anomaly strength from electric field proxies, J. Geophys. Res., 113, A09310, doi:10.1029/2007JA012781, 2008.

Sultan, P. J.: Linear theory and modeling of the Rayleigh-Taylor instability leading to the occurrence of equatorial spread F, J. Geophys. Res., 101, 26875-26891, 1996.

Thampi, S. V., Ravindran, S., Pant, T. K., Devasia, C. V., and Sridharan, R.: Seasonal dependence of the "forecast parameter" based on the EIA characteristics for the prediction of Equatorial Spread F (ESF), Ann. Geophys., 26, 1751-1757, 2008, http://www.ann-geophys.net/26/1751/2008/.

Tulasi Ram, S., Rama Rao, P. V. S., Prasad, D. S. V. V. D., Niranjan, K., Raja Babu, A., Sridharan, R., Devasia, C. V., and Sudha Ravindran: The combined effects of electrojet strength and the geomagnetic activity (Kp-index) on the post sunset height rise of the F-layer and its role in the generation of ESF during high and low solar activity periods, Ann. Geophys., 25, 2007-2017, 2007, http://www.ann-geophys.net/25/2007/2007/. 